\title{
Altered synaptic connections and inhibitory network of the primary somatosensory cortex in chronic pain
}

\author{
Yoo Rim Kim ${ }^{1,3}$ and Sang Jeong $\operatorname{Kim}^{1,2,3, *}$ \\ Departments of ${ }^{1}$ Physiology, ${ }^{2}$ Biomedical Sciences, Seoul National University College of Medicine, ${ }^{3}$ Neuroscience Research Institute, Seoul National University \\ College of Medicine, Seoul 03080, Korea
}

\section{ARTICLE INFO}

Received December 6, 2021

Revised December 21, 2021

Accepted December 22, 2021

*Correspondence

Sang Jeong Kim

E-mail: sangjkim@snu.ac.kr

\section{Key Words}

Chronic pain

Cortical circuit

Inhibitory network

Neuropathic pain

Primary somatosensory cortex
ABSTRACT Chronic pain is induced by tissue or nerve damage and is accompanied by pain hypersensitivity (i.e., allodynia and hyperalgesia). Previous studies using in vivo two-photon microscopy have shown functional and structural changes in the primary somatosensory (S1) cortex at the cellular and synaptic levels in inflammatory and neuropathic chronic pain. Furthermore, alterations in local cortical circuits were revealed during the development of chronic pain. In this review, we summarize recent findings regarding functional and structural plastic changes of the S1 cortex and alteration of the $\mathrm{S} 1$ inhibitory network in chronic pain. Finally, we discuss potential neuromodulators driving modified cortical circuits and suggest further studies to understand the cortical mechanisms that induce pain hypersensitivity.

\section{INTRODUCTION}

Prolonged tissue damage or nerve injury can lead to chronic pain, such as inflammatory or neuropathic pain, in which a variety of changes occur throughout the nociceptive pathways, from the periphery to the cortex [1-4]. Many researchers have identified changes in the expression of receptors and channels in the peripheral nervous system and central nervous system in chronic pain models [3]. Additionally, local circuits and/or proportions of cell types have been reported to change in pain-related regions [510]. Under chronic pain conditions, hyperexcitability, reorganization, and structural brain changes are observed in the pain matrix brain regions, such as the primary somatosensory (S1) cortex and anterior cingulate cortex $[11,12]$, with modifications in their functional connections [13]. Recently, with advanced two-photon imaging and cell type identification techniques using genetically modified mice, research to elucidate the cortical mechanisms of chronic pain has been actively conducted. Increased activities in inhibitory and excitatory neurons in the S1 cortex have been reported in chronic pain models [14-16], and plastic structural changes have been observed in the $\mathrm{S} 1$ cortex in neuropathic pain models [17-19]. Pain relief following S1 manipulation [15,19] in chronic pain suggests that the S1 cortex is deeply involved in the development and maintenance of chronic pain.

Neural circuits in the S1 cortex consist of pyramidal neurons (PNs) and several subtypes of inhibitory neurons. The activity of PNs is appropriately regulated within a local inhibitory circuit composed of three major subtypes of inhibitory neurons: somatostatin (SOM), parvalbumin (PV), and vasoactive intestinal polypeptide (VIP)-expressing interneurons [20]. SOM and PV inhibitory neurons are known to contribute to the dendritic and perisomatic inhibition of PNs, respectively [21,22]. In contrast, VIP neurons are known to suppress other subtypes of inhibitory neurons [23]. Previous studies have reported alterations in the activities of subtypes of inhibitory neurons in models of chronic pain, suggesting their potential as targets for chronic pain relief
(1) \& This is an Open Access article distributed under the terms of the Creative Commons Attribution Non-Commercial License, which permits unrestricted non-commercial use, distribution, and reproduction in any medium, provided the original work is properly cited. Copyright @ Korean J Physiol Pharmacol, pISSN 1226-4512, eISSN 2093-3827
Author contributions: Y.R.K. conceived the idea, and wrote and revised the manuscript. S.J.K. supervised and revised the manuscript. 
$[15,16]$. However, it remains unclear as to which neuromodulators drive such changes in local circuits.

Cholinergic input from the basal forebrain to the $\mathrm{S} 1$ cortex is suggested to act on inhibitory neurons to modulate PN activity. Another potential factor is the noradrenergic modulation of the S1 local circuitry. In this article, we review the plastic changes occurring at the neuronal and circuit levels of the S1 cortex in chronic pain models, which were assessed mainly using brain imaging studies. In addition, we discuss the causative neuromodulators that drive local circuit changes in chronic pain and suggest directions for further research to alleviate chronic pain symptoms and understand cortical mechanisms.

\section{NEURAL PLASTIC CHANGES IN THE S1 CORTEX IN CHRONIC PAIN}

Brain imaging studies (e.g., functional magnetic resonance imaging [fMRI] or micro-positron emission tomography [microPET]) in both humans and animal models have shown increased activation intensity, somatotopic reorganization, and altered cortical thickness of the S1 cortex, as well as modified connectivity patterns in the pain matrix under chronic pain conditions $[11,13,24,25]$. These findings suggest that the $\mathrm{S} 1$ cortex is associated with the development of chronic pain.

In recent years, using in vivo two-photon microscopy imaging, functional and structural changes of the $\mathrm{S} 1$ cortex have been reported at the individual cell and synapse levels in rodent chronic pain models. In mice with chronic pain induced by spinal nerve injury, the fraction of active neurons in the $\mathrm{S} 1$ cortex significantly increased two days after injury, and the fluorescence of the active neurons was higher than that in sham-operated mice [26]. Previous imaging studies have also reported that the activity of L5 PNs in the S1 cortex was persistently elevated, and L2/3 PNs exhibited higher activity in peripheral nerve-injured mice than in sham mice [15,16]. Cichon et al. [15] performed an experiment to inhibit peripheral sensory inputs by local application of the sodium channel blocker tetrodotoxin to the sciatic nerve, and found that inhibition of peripheral inputs did not reduce the elevated somatic $\mathrm{Ca}^{2+}$ activity of S1 L5 PNs in nerve-injured mice, unlike in sham mice, suggesting that the hyperactivity of S1 PNs can be due to some major changes in the S1 cortex that are not simply driven by peripheral inputs. In addition, the functional connectivity between $\mathrm{S} 1 \mathrm{~L} 2 / 3$ active neurons was positively increased in response to peripheral stimulation in an inflammatory chronic pain model [27]. Further, Eto et al. [28] showed that both spontaneous activity and evoked activity to sensory stimulation of $\mathrm{S} 1$ L2/3 neurons increased in the same chronic pain model. The authors also confirmed that evoked activity of inhibitory neurons as well as excitatory neurons in S1 L2/3 was increased upon sensory stimulation under inflammatory chronic pain conditions [28]. Interestingly, even though a $\mathrm{GABA}_{\mathrm{A}}$ receptor agonist was applied to the $\mathrm{S} 1 \mathrm{~L} 2 / 3$ to facilitate overall inhibitory action, pain behavior was transiently alleviated. This result suggest that an overall increase in inhibitory action of S1 L2/3 is insufficient to fundamentally counteract $\mathrm{S} 1$ hyperactivity in chronic pain.

Kim and Nabekura [18] demonstrated that remodeling of cortical synapses in the $\mathrm{S} 1$ cortex is associated with the development of chronic neuropathic pain induced by peripheral nerve injury. In particular, they showed that the dendritic spine turnover of L5 PNs was markedly increased during the developmental state of chronic pain, and the volume of new spines formed after nerve injury continued to increase. With structural changes in dendritic spines, increased axonal bouton turnover in the $\mathrm{S} 1$ cortex was observed in the developmental state of chronic pain [17]. A subsequent study showed that peripheral nerve injury induced upregulation of the metabotropic glutamate receptor 5 signaling in S1 astrocytes, resulting in the release of synaptogenic thrombospondin 1 (TSP-1) from the S1 astrocytes. Overexpression of TSP-1 in the S1 cortex led to increased dendritic spine turnover in S1 pyramidal neurons in chronic pain. Knockdown of TSP-1 expression in the $\mathrm{S} 1$ cortex using siRNA reduced spine turnover of S1 PNs and alleviated pain behavior [19]. These findings collectively suggest that structural plastic changes in the S1 cortex are attributed to $\mathrm{S} 1$ astrocyte activation in the developmental state of chronic pain.

\section{LOCAL CIRCUIT CHANGES IN THE S1 CORTEX IN CHRONIC PAIN}

At the individual cell level, it is well accepted that the spontaneous activity of S1 PNs and their evoked activity in response to peripheral sensory stimulation are increased under chronic pain conditions. In addition, Eto et al. [14] reported that both excitatory and inhibitory neurons exhibited increased somatic calcium activity in chronic pain mice, but the hyperactivity of $\mathrm{S} 1$ excitatory neurons could not be counteracted by an overall increase in GABAergic neuron activity in the $\mathrm{S} 1$ cortex. The mechanisms by which the S1 neuronal circuits, which are composed of excitatory pyramidal neurons and the distinct subtypes of GABAergic interneurons, reorganize to lead to $\mathrm{S} 1$ hyperactivity in chronic pain are unknown. A recent study on the medial prefrontal cortex (mPFC) found that nerve injury altered the excitability of distinct subtypes of GABAergic neurons in a sex-specific manner [29]. A chronic pain study performed in the ACC demonstrated that the loss of inhibitory synapses onto excitatory neurons and excitatory synapses onto inhibitory neurons resulted in a disinhibited cortical network [10]. In a model of chronic inflammatory pain, increased synchronization and connectivity among active neurons of the S1 cortex to peripheral sensory stimulation was observed. On the other hand, the correlation between PV-expressing inhibitory neurons decreased without a change in the power of calcium transient and frequency events over the same period [27]. This 
means that there is a critical change in the inhibitory network, which may imply that local circuits, including PNs, are modified and that PNs become hyperactive in chronic pain.

Recent imaging studies of the S1 cortex have found that the local inhibitory networks are modified in chronic pain induced by peripheral nerve injury. Cichon et al. [15] identified alterations in neuronal calcium activity in three major subtypes (SOM, PV, and VIP neurons) of S1 L2/3 interneurons, along with hyperactivity of L5 and L2/3 PNs in chronic neuropathic pain. The activities of SOM and PV neurons were reduced 1 month after induction of chronic pain, and in particular, the activity of SOM neurons was halved, whereas the activity of VIP neurons dramatically increased under the same conditions. The increase in SOM activity through pharmacogenetic techniques decreased the calcium activities of L5 and L2/3 PNs, and also debilitated allodynia. On the other hand, increasing PV activity was insufficient to alleviate allodynia. Wei et al. [16] also confirmed the cell-type-specific changes in the S1 inhibitory circuits that contribute to the development of chronic neuropathic pain. The authors showed that the altered activities of each type of $\mathrm{S} 1$ neuron in chronic pain were reversed through electroacupuncture in the periphery, and found that hypersensitivity could be alleviated by CB1R-induced modulation of the activity of VIP neurons [16]. These findings suggest that distinct subtypes of S1 inhibitory neurons in chronic pain shift their activity toward S1 PNs hyperactivity, and that reversing the shifted activity of inhibitory neurons may be a therapeutic strategy to suppress the onset of chronic pain.

\section{POTENTIAL MECHANISMS DRIVING MODIFICATIONS OF LOCAL CIRCUITS IN THE S1 CORTEX IN CHRONIC PAIN}

Previous studies on nociceptive pathways have suggested that alterations in inhibitory transmission are implicated in the development of chronic pain [10,30,31]. Many of the aforementioned studies have shown an impaired S1 inhibitory network in which VIP neuron activity is upregulated and SOM/PV neuron activity is downregulated, which causes enhancement of S1 PN activity in chronic pain. However, it is unknown what drives these changes in the local circuit of the $S 1$ cortex under chronic pain conditions.

In the cortical circuit, the three major subtypes of GABAergic neurons are interconnected, and inhibit each other, and have the following characteristics (Fig. 1A) [23]. VIP neurons inhibit SOM and PV neurons without PN inhibition, and preferentially suppress the firing of SOM neurons. SOM and PV neurons, in turn, inhibit the PNs. SOM neurons strongly inhibit other populations with little inhibition of each other, whereas PV neurons mainly inhibit each other. In the connected relationships, an increase in VIP activity inevitably leads to a decrease in SOM/PV activity and hyperactivity in PNs in chronic pain (Fig. 1B), and reversal of SOM and VIP activities was possibly able to alleviate chronic pain symptoms. Modulation of PV activity did not alleviate allodynia, which may be due to the large difference between SOM synapses onto tuft dendrites of PNs and PV synapses onto the somatic membrane of PNs [21,22]. Therefore, upregulation of SOM activity was effective in chronic pain, but the ultimate solution would be to tune the VIP activity that regulates the firing of other subtypes of inhibitory neurons.

VIP neurons have recently been widely studied for their disinhibitory roles in sharpening cortical functions during sensory processing in multiple areas of the neocortex [32-35]. Activation of VIP neurons in the auditory cortex transiently suppresses SOM and PV neurons that control the input and output of principal neurons [35]. In particular, during an auditory discrimination task, uniform activation of VIP neurons enhanced the gain of a functional subpopulation of principal neurons. Acetylcholine (ACh) has been suggested to influence the disinhibitory action of
A

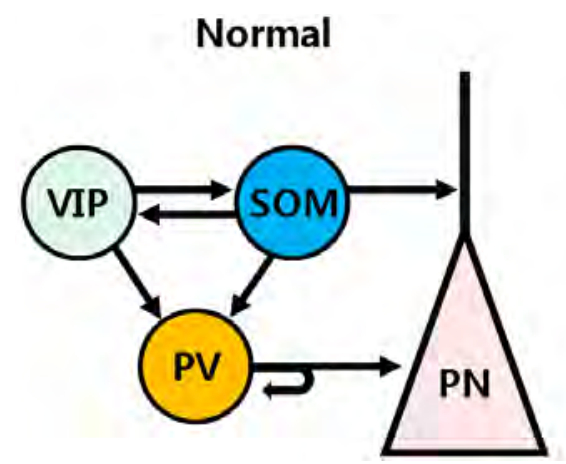

B

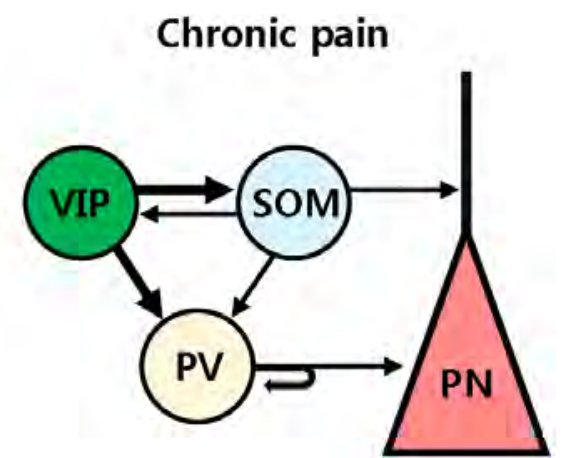

Fig. 1. Local inhibitory circuits are modified in chronic pain. (A) Under normal conditions, pyramidal neurons (PN) are appropriately modulated by mainly somatostatin (SOM) and parvalbumin (PV)-expressing inhibitory neurons. Vasoactive intestinal polypeptide (VIP)-expressing inhibitory neurons primarily inhibit other subtypes of inhibitory neuron, and preferentially suppresses SOM activity. SOM and PV neurons contribute to tuft dendritic and perisomatic inhibition of pyramidal neurons, respectively. (B) Tissue or nerve injury alters local inhibitory circuits towards hyperactivity of pyramidal neurons, leading to chronic pain. Enhanced VIP activity reduces SOM and PV activities and ultimately enhances PN hyperactivity. 
VIP. Unlike other cell populations, in the barrel cortex, VIP neurons are depolarized during active whisking [34]. The optogenetic release of ACh selectively depolarized VIP neurons, indicating that VIP neurons selectively receive nicotinic input.

Cholinergic afferents differentially target each subtype of cortical GABAergic neurons, while VIP neurons exhibit a higher expression of nicotinic receptors compared to other subtypes [36]. VIP neurons have also been reported to prominently express non$\alpha 7$-subtypes of nicotinic receptors [37]. In addition, it has been suggested that basal forebrain cholinergic afferents to the S1 cortex drive inhibitory neurons, but not PVs, through $\alpha 7$-subtypes of nicotinic acetylcholine receptor (nAChRs) in $\mathrm{L} 1$ and $\mathrm{L} 2 / 3$, thus reducing net inhibitory input to PNs $[38,39]$. Application of ACh in anesthetized rats enhanced the sensory-evoked discharge of the S1 neurons [40]. However, some neurons responded to tactile stimulation only in the presence of ACh, suggesting that cholinergic modulation by specific subpopulations may exist in the $\mathrm{S} 1$ cortex. Although the S1 cortex is known to receive cholinergic inputs from basal forebrain projection neurons, few studies have directly validated the relationship between altered cortical networks in chronic pain and cholinergic modulation. It is necessary to directly prove whether the alteration of VIP activity is attributed to cholinergic input in chronic pain. Moreover, it is necessary to verify whether modified inhibitory circuit and PN hyperactivity through ACh are the result of ACh's direct action on the S1 cortex or due to external factors (e.g., thalamocortical input) (Fig. 2A).

Another potential factor that drives circuit changes in chronic pain is noradrenergic action on the $\mathrm{S} 1$ cortex. The main source of norepinephrine (NE) in the cortex is the locus coeruleus (LC), which contains noradrenergic neurons projecting to multiple areas of the cortex (e.g., S1 cortex, auditory cortex, and prefrontal cortex) [41-43]. LC activity is associated with pain inhibition, and intense pain induces LC activity. Although the LC is known to be involved in pain suppression [44,45], recent findings suggest that it contributes to the development and maintenance of chronic pain after nerve injury. In short-term chronic pain ( 14 days), noxious stimulation altered the evoked activity of the contralateral LC, whereas both spontaneous activity and noxious-evoked responses were changed in the contralateral and ipsilateral LC in the long-term state (28 days) after nerve injury [46]. This means that the ascending pathway is bilaterally engaged in the maintenance stage of chronic pain. In another model of chronic neuropathic pain, innocuous tactile stimulation increased neuronal activity in the LC [47]. Selective destruction of LC neurons 2 weeks before nerve injury alleviated allodynia and hyperalgesia after nerve injury. Moreover, 2 weeks after nerve injury, where pain hypersensitivity was fully developed, lidocaine applied directly into the LC reduced pain hypersensitivity. These findings collectively suggest that LC activation induced by nerve injury contributes to the development and maintenance of chronic neuropathic pain. It has also been reported that the expression and sensitivity of alpha 2-adrenoceptor in the LC are enhanced in long-term neuropathic pain [48]. Local administration of alpha 2-adrenoceptor agonists into the LC significantly decreased extracellular norepinephrine
A

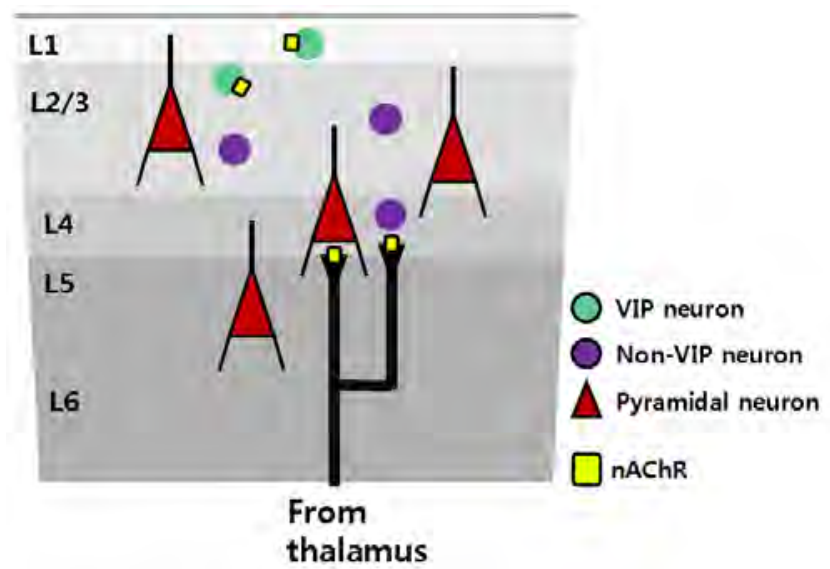

B

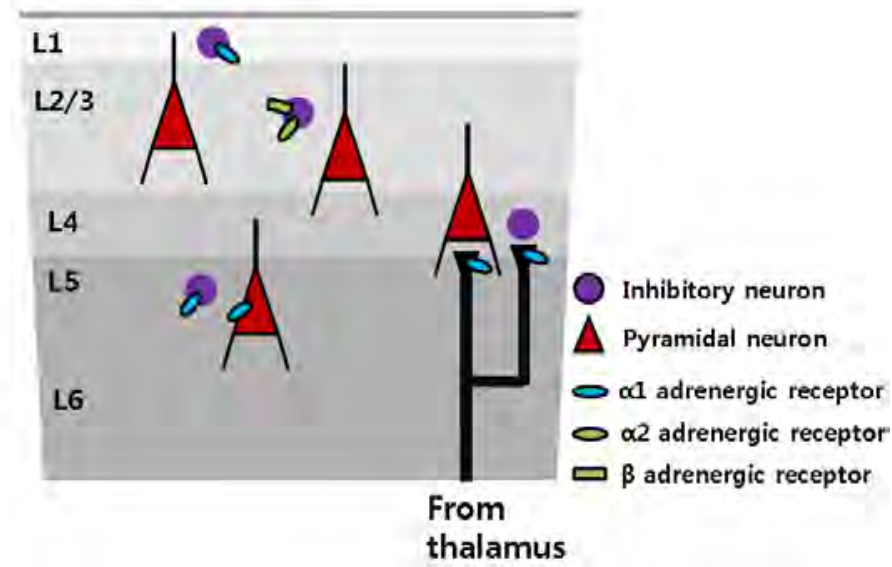

Fig. 2. Potential local circuit plasticity evoked by cholinergic and noradrenergic inputs in chronic pain. (A) Acetylcholine is the one of the potential neuromodulators that drives circuit changes in chronic pain. Cholinergic input from basal forebrain projection neurons can differentially target each subtype of cortical GABAergic neurons. Vasoactive intestinal polypeptide (VIP) neurons are mainly located in L1 and L2/3, and, in particular, exhibit a higher expression of nicotinic receptors compared to other subtypes. In chronic pain, VIPs expressing nicotinic acetylcholine receptors (nAChR) can be driven by cholinergic inputs and reduce the net inhibitory effects on pyramidal neurons. Along with the action on nAChRs in VIP neurons, the activation of presynaptic $n A C h R s$ in thalamocortical neurons may modulate thalamocortical transmission in layer 4 of the S1 cortex in chronic pain. (B) Another potential factor is noradrenergic action of the S1 cortex during chronic pain conditions. Noradrenergic inputs projected from the locus coeruleus may exert layer-specific modulation by the action of different types of adrenergic receptors in the S1 cortex. Norepinephrine (NE) regulates the excitability of $\mathrm{L} 1$ and L2/3 excitatory neurons via presynaptic alpha-1 and alpha-2/beta-adrenergic receptors, respectively, on inhibitory neurons. In addition, NE modulates the synaptic responsiveness of $L 5$ pyramidal neurons via alpha-1 receptors. NE may also act on presynaptic thalamocortical neurons, resulting in local circuit plasticity. 
concentration in the $\mathrm{mPFC}$ but not $\mathrm{LC}$, suggesting that $\mathrm{NE}$ release of noradrenergic projections on the $\mathrm{MPFC}$ is reduced through the action of alpha 2-adrenoceptors in the LC.

$\mathrm{NE}$ axons project onto the S1 cortex, but the action of NE on the $\mathrm{S} 1$ cortex is not well understood. Some of the $\mathrm{S} 1$ neurons were activated by NE or alpha-1 agonists, but some showed reduced responses to NE or beta-agonists [49,50]. In the S1 barrel cortex, $\mathrm{NE}$ and alpha-1 agonists increased or decreased the synaptic responsiveness of L5 PNs to differentially defined classes of L5 neurons. A recent study showed that $\mathrm{NE}$ axons projecting into the $\mathrm{S} 1$ barrel cortex responded reliably to whisker stimulation. After associative auditory fear conditioning, NE axons showed an increase in calcium activity only for $\mathrm{CS}^{+}$, indicating experiencedependent plasticity. In addition, a nonlinear relationship exists between the NE axons and local dendrites in the S1 cortex [51]. These results imply that NE can sufficiently modulate the $\mathrm{S} 1$ local circuitry under physiological and pathological conditions. A previous study in the auditory cortex suggested layer-specific noradrenergic modulation by the action of different receptor types [52]. NE decreased the amplitude of evoked inhibitory postsynaptic currents (eIPSCs) of L1 excitatory neurons via alpha-1 adrenergic receptors, as well as increased the amplitude of eIPSCs of L2/3 excitatory neurons via alpha-2 and beta-adrenergic receptors. This NE-induced modulation was shown to be a presynaptic contribution. It is necessary to verify that NE projections directly affect $\mathrm{S} 1$ circuitry and ultimately lead to PN hyperactivity (Fig. 2B).

\section{CONCLUSIONS AND PERSPECTIVES}

In vivo two-photon imaging studies have revealed functional and structural plastic changes in the S1 cortex at the individual cell and synaptic levels in rodent models of chronic pain. Both spontaneous and sensory-evoked activities are elevated in the L2/3 and L 5 neurons of the S1 cortex in inflammatory and neuropathic chronic pain. S1 synaptic remodeling associated with S1 astrocyte reactivation also occurs during the development of neuropathic pain. As mainly reviewed in this paper, the S1 local inhibitory circuit was modified for $\mathrm{S} 1$ hyperexcitability in chronic pain. Unsolved questions remain as to which neuromodulator drives such changes in the S1 cortex in chronic pain. ACh and NE can induce S1 PN hyperactivity by modifying the inhibitory network or by acting directly on the PNs. It is necessary to confirm whether cholinergic or noradrenergic modulation directly acts on the $S 1$ cortex.

Finally, the cortical mechanism by which hypersensitivity occurs needs to be clarified. Individual neurons in the S1 cortex have intrinsic response properties that specifically respond to sensory stimulation $[53,54]$. The aforementioned changes in the $S 1$ cortex may also be related to alterations in the response properties of S1 neurons, such as changes in response intensity or response preference to painful and non-painful stimuli un- der chronic pain conditions. What is the relationship between alterations in response properties in a specific cell population of $\mathrm{S} 1$ and pain hypersensitivity in chronic pain? Chronic pain is characterized by allodynia and hyperalgesia, which impair the quality of life and lead to hyperexcitability of the S1 cortex [4]. It is unknown whether the hypersensitivity is due to the altered activity of nociceptive neurons or if other populations are newly recruited in chronic pain. In our previous study [55], we classified the cell types of $S 1$ individual neurons according to their response patterns to painful and non-painful stimuli. Although excitatory and inhibitory neurons were not distinguished in the study, we were able to identify pain-intensity coding neurons, innocuous preferred neurons, and noxious preferred neurons. Alterations in the response properties of each cell population to sensory stimulation before and after the onset of chronic pain may be associated with behavioral hypersensitivity. To understand the cortical mechanisms of allodynia and hyperalgesia, it would be meaningful to perform experiments by regulating the activity of each cell population that shows changes in response properties.

\section{FUNDING}

This study was supported by National Research Foundation of Korea grants funded by the Korea government to YRK (NRF2020R1I1A1A01065791) and to SJK (NRF-2018R1A5A2025964 and NRF-2017M3C7A1029611).

\section{ACKNOWLEDGEMENTS}

None.

\section{CONFLICTS OF INTEREST}

The authors declare no conflicts of interest.

\section{REFERENCES}

1. Woolf CJ; American College of Physicians; American Physiological Society. Pain: moving from symptom control toward mechanismspecific pharmacologic management. Ann Intern Med. 2004;140: 441-451.

2. Baron R. Mechanisms of disease: neuropathic pain--a clinical perspective. Nat Clin Pract Neurol. 2006;2:95-106.

3. Latremoliere A, Woolf CJ. Central sensitization: a generator of pain hypersensitivity by central neural plasticity. J Pain. 2009;10:895-926.

4. Costigan M, Scholz J, Woolf CJ. Neuropathic pain: a maladaptive response of the nervous system to damage. Annu Rev Neurosci. 2009;32:1-32.

5. Woolf CJ, Shortland P, Coggeshall RE. Peripheral nerve injury trig- 
gers central sprouting of myelinated afferents. Nature. 1992;355:7578.

6. Woodbury CJ, Kullmann FA, McIlwrath SL, Koerber HR. Identity of myelinated cutaneous sensory neurons projecting to nocireceptive laminae following nerve injury in adult mice. J Comp Neurol. 2008;508:500-509.

7. Kohno T, Moore KA, Baba H, Woolf CJ. Peripheral nerve injury alters excitatory synaptic transmission in lamina II of the rat dorsal horn. J Physiol. 2003;548(Pt 1):131-138.

8. Baba H, Doubell TP, Woolf CJ. Peripheral inflammation facilitates Abeta fiber-mediated synaptic input to the substantia gelatinosa of the adult rat spinal cord. J Neurosci. 1999;19:859-867.

9. Gwak YS, Hulsebosch CE. Neuronal hyperexcitability: a substrate for central neuropathic pain after spinal cord injury. Curr Pain Headache Rep. 2011;15:215-222.

10. Blom SM, Pfister JP, Santello M, Senn W, Nevian T. Nerve injuryinduced neuropathic pain causes disinhibition of the anterior cingulate cortex. J Neurosci. 2014;34:5754-5764.

11. Seifert F, Maihöfner C. Central mechanisms of experimental and chronic neuropathic pain: findings from functional imaging studies. Cell Mol Life Sci. 2009;66:375-390.

12. Bak MS, Park H, Kim SK. Neural plasticity in the brain during neuropathic pain. Biomedicines. 2021;9:624.

13. Kim CE, Kim YK, Chung G, Jeong JM, Lee DS, Kim J, Kim SJ. Large-scale plastic changes of the brain network in an animal model of neuropathic pain. Neuroimage. 2014;98:203-215.

14. Eto K, Ishibashi H, Yoshimura T, Watanabe M, Miyamoto A, Ikenaka K, Moorhouse AJ, Nabekura J. Enhanced GABAergic activity in the mouse primary somatosensory cortex is insufficient to alleviate chronic pain behavior with reduced expression of neuronal potassium-chloride cotransporter. J Neurosci. 2012;32:16552-16559.

15. Cichon J, Blanck TJJ, Gan WB, Yang G. Activation of cortical somatostatin interneurons prevents the development of neuropathic pain. Nat Neurosci. 2017;20:1122-1132.

16. Wei JA, Hu X, Zhang B, Liu L, Chen K, So KF, Li M, Zhang L. Electroacupuncture activates inhibitory neural circuits in the somatosensory cortex to relieve neuropathic pain. iScience. 2021;24:102066.

17. Kim SK, Kato G, Ishikawa T, Nabekura J. Phase-specific plasticity of synaptic structures in the somatosensory cortex of living mice during neuropathic pain. Mol Pain. 2011;7:87.

18. Kim SK, Nabekura J. Rapid synaptic remodeling in the adult somatosensory cortex following peripheral nerve injury and its association with neuropathic pain. J Neurosci. 2011;31:5477-5482.

19. Kim SK, Hayashi H, Ishikawa T, Shibata K, Shigetomi E, Shinozaki Y, Inada H, Roh SE, Kim SJ, Lee G, Bae H, Moorhouse AJ, Mikoshiba K, Fukazawa Y, Koizumi S, Nabekura J. Cortical astrocytes rewire somatosensory cortical circuits for peripheral neuropathic pain. J Clin Invest. 2016;126:1983-1997.

20. DeFelipe J, López-Cruz PL, Benavides-Piccione R, Bielza C, Larrañaga $\mathrm{P}$, Anderson S, Burkhalter A, Cauli B, Fairén A, Feldmeyer D, Fishell G, Fitzpatrick D, Freund TF, González-Burgos G, Hestrin S, Hill S, Hof PR, Huang J, Jones EG, Kawaguchi Y, et al. New insights into the classification and nomenclature of cortical GABAergic interneurons. Nat Rev Neurosci. 2013;14:202-216.

21. Cichon J, Gan WB. Branch-specific dendritic $\mathrm{Ca}^{2+}$ spikes cause persistent synaptic plasticity. Nature. 2015;520:180-185.

22. Beierlein M, Gibson JR, Connors BW. Two dynamically distinct inhibitory networks in layer 4 of the neocortex. $J$ Neurophysiol. 2003;90:2987-3000

23. Pfeffer CK, Xue M, He M, Huang ZJ, Scanziani M. Inhibition of inhibition in visual cortex: the logic of connections between molecularly distinct interneurons. Nat Neurosci. 2013;16:1068-1076.

24. Cha MH, Kim DS, Cho ZH, Sohn JH, Chung MA, Lee HJ, Nam TS, Lee BH. Modification of cortical excitability in neuropathic rats: a voltage-sensitive dye study. Neurosci Lett. 2009;464:117-121.

25. Endo T, Spenger C, Hao J, Tominaga T, Wiesenfeld-Hallin Z, Olson $\mathrm{L}, \mathrm{Xu}$ XJ. Functional MRI of the brain detects neuropathic pain in experimental spinal cord injury. Pain. 2008;138:292-300.

26. Xiong W, Ping X, Ripsch MS, Chavez GSC, Hannon HE, Jiang K, Bao C, Jadhav V, Chen L, Chai Z, Ma C, Wu H, Feng J, Blesch A, White FA, Jin X. Enhancing excitatory activity of somatosensory cortex alleviates neuropathic pain through regulating homeostatic plasticity. Sci Rep. 2017;7:12743.

27. Okada T, Kato D, Nomura Y, Obata N, Quan X, Morinaga A, Yano H, Guo Z, Aoyama Y, Tachibana Y, Moorhouse AJ, Matoba O, Takiguchi T, Mizobuchi S, Wake H. Pain induces stable, active microcircuits in the somatosensory cortex that provide a therapeutic target. Sci Adv. 2021;7:eabd8261.

28. Eto K, Wake H, Watanabe M, Ishibashi H, Noda M, Yanagawa Y, Nabekura J. Inter-regional contribution of enhanced activity of the primary somatosensory cortex to the anterior cingulate cortex accelerates chronic pain behavior. J Neurosci. 2011;31:7631-7636.

29. Jones AF, Sheets PL. Sex-specific disruption of distinct mPFC inhibitory neurons in spared-nerve injury model of neuropathic pain. Cell Rep. 2020;31:107729.

30. Coull JA, Boudreau D, Bachand K, Prescott SA, Nault F, Sík A, De Koninck P, De Koninck Y. Trans-synaptic shift in anion gradient in spinal lamina I neurons as a mechanism of neuropathic pain. Nature. 2003;424:938-942.

31. Knabl J, Witschi R, Hösl K, Reinold H, Zeilhofer UB, Ahmadi S, Brockhaus J, Sergejeva M, Hess A, Brune K, Fritschy JM, Rudolph U, Möhler H, Zeilhofer HU. Reversal of pathological pain through specific spinal GABAA receptor subtypes. Nature. 2008;451:330-334.

32. Harding EK, Salter MW. VIP cortical conductors set the tone for chronic pain. Nat Neurosci. 2017;20:1037-1038.

33. Pakan JM, Lowe SC, Dylda E, Keemink SW, Currie SP, Coutts CA, Rochefort NL. Behavioral-state modulation of inhibition is contextdependent and cell type specific in mouse visual cortex. Elife. 2016; 5:e14985.

34. Gasselin C, Hohl B, Vernet A, Crochet S, Petersen CCH. Cell-typespecific nicotinic input disinhibits mouse barrel cortex during active sensing. Neuron. 2021;109:778-787.e3.

35. Pi HJ, Hangya B, Kvitsiani D, Sanders JI, Huang ZJ, Kepecs A. Cortical interneurons that specialize in disinhibitory control. Nature. 2013;503:521-524.

36. Poorthuis RB, Enke L, Letzkus JJ. Cholinergic circuit modulation through differential recruitment of neocortical interneuron types during behaviour. J Physiol. 2014;592:4155-4164.

37. Arroyo S, Bennett C, Aziz D, Brown SP, Hestrin S. Prolonged disynaptic inhibition in the cortex mediated by slow, non- $\alpha 7$ nicotinic excitation of a specific subset of cortical interneurons. J Neurosci. 2012;32:3859-3864.

38. Hedrick T, Waters J. Acetylcholine excites neocortical pyramidal neurons via nicotinic receptors. J Neurophysiol. 2015;113:2195-2209. 
39. Brombas A, Fletcher LN, Williams SR. Activity-dependent modulation of layer 1 inhibitory neocortical circuits by acetylcholine. $J$ Neurosci. 2014;34:1932-1941.

40. Donoghue JP, Carroll KL. Cholinergic modulation of sensory responses in rat primary somatic sensory cortex. Brain Res. 1987;408:367-371.

41. Morrison JH, Foote SL. Noradrenergic and serotoninergic innervation of cortical, thalamic, and tectal visual structures in Old and New World monkeys. J Comp Neurol. 1986;243:117-138.

42. McBurney-Lin J, Lu J, Zuo Y, Yang H. Locus coeruleus-norepinephrine modulation of sensory processing and perception: a focused review. Neurosci Biobehav Rev. 2019;105:190-199.

43. Sara SJ, Bouret S. Orienting and reorienting: the locus coeruleus mediates cognition through arousal. Neuron. 2012;76:130-141.

44. Yoshimura M, Furue H. In vivo electrophysiological analysis of mechanisms of monoaminergic pain inhibitory systems. Pain. 2017; 158 Suppl 1:S85-S91.

45. North RA, Yoshimura M. The actions of noradrenaline on neurones of the rat substantia gelatinosa in vitro. J Physiol. 1984;349:43-55.

46. Alba-Delgado C, Mico JA, Berrocoso E. Neuropathic pain increases spontaneous and noxious-evoked activity of locus coeruleus neurons. Prog Neuropsychopharmacol Biol Psychiatry. 2021;105:110121.

47. Brightwell JJ, Taylor BK. Noradrenergic neurons in the locus coeruleus contribute to neuropathic pain. Neuroscience. 2009;160:174185.

48. Alba-Delgado C, Llorca-Torralba M, Horrillo I, Ortega JE, Mico JA, Sánchez-Blázquez P, Meana JJ, Berrocoso E. Chronic pain leads to concomitant noradrenergic impairment and mood disorders. Biol Psychiatry. 2013;73:54-62.
49. Waterhouse BD, Mouradian R, Sessler FM, Lin RC. Differential modulatory effects of norepinephrine on synaptically driven responses of layer $\mathrm{V}$ barrel field cortical neurons. Brain Res. 2000;868:39-47.

50. Devilbiss DM, Waterhouse BD. Norepinephrine exhibits two distinct profiles of action on sensory cortical neuron responses to excitatory synaptic stimuli. Synapse. 2000;37:273-282.

51. Deitcher Y, Leibner Y, Kutzkel S, Zylbermann N, London M. Nonlinear relationship between multimodal adrenergic responses and local dendritic activity in primary sensory cortices. BioRxiv. 814657 [Preprint]. 2019 [cited 2021 Dec 5]. Available from: https://doi. org/10.1101/814657.

52. Salgado H, Garcia-Oscos F, Patel A, Martinolich L, Nichols JA, Dinh L, Roychowdhury S, Tseng KY, Atzori M. Layer-specific noradrenergic modulation of inhibition in cortical layer II/III. Cereb Cortex. 2011;21:212-221.

53. Lamour Y, Willer JC, Guilbaud G. Rat somatosensory (SmI) cortex: I. Characteristics of neuronal responses to noxious stimulation and comparison with responses to non-noxious stimulation. Exp Brain Res. 1983;49:35-45.

54. Chung JM, Surmeier DJ, Lee KH, Sorkin LS, Honda CN, Tsong Y, Willis WD. Classification of primate spinothalamic and somatosensory thalamic neurons based on cluster analysis. J Neurophysiol. 1986;56:308-327.

55. Kim YR, Kim CE, Yoon H, Kim SK, Kim SJ. S1 Employs featuredependent differential selectivity of single cells and distributed patterns of populations to encode mechanosensations. Front Cell Neurosci. 2019;13:132. 